\title{
The dual route model and the developmental dyslexias
}

\author{
Anne Castles* \\ The University of Melbourne, Australia
}

This review discusses the important contribution made by one particular theoretical model of reading - the dual route model - to the identification and understanding of different varieties of developmental dyslexia. The model itself is first outlined, and the particular types of reading disorder that would be predicted to occur based on this model are described. The evidence for the existence of these patterns of reading disability is then reviewed and advances that have been made in understanding their basis and aetiology are described. Finally, some suggestions are made about how best to take research on heterogeneity in developmental dyslexia forward, moving away from distinct subtypes and more towards model-based reading profiles.

\section{Introduction}

A single term is widely used to describe the condition of children with a reading problem that is unexpected given their abilities and educational opportunities: 'dyslexia'. However, researchers in education and psychology have long been aware that developmental reading disorders are unlikely to occur in only one form. Rather, it is understood that a complex process such as reading will be likely to fail in an equally complex range of ways. The quote below comes from a report of the standardization of an Australian reading test published as long ago as 1935. The focus on the multifaceted nature of reading is apparent:

The question of distinguishing between the different aspects or phases of reading is one which has practical importance. For example, any attempt to remedy the serious weaknesses in reading commonly found in individual school children must be based on a differentiation of those phases of the reading process which are largely independent of one another. The proof of the degree of independence is a technical matter but will lead eventually to the provision of diagnostic tests which will reveal to the practical teacher

\footnotetext{
*Department of Psychology, University of Melbourne, Parkville, Victoria 3010, Australia. Email: acastles@unimelb.edu.au
} 
the particular phases of reading in which a given child requires special help. (McIntyre \& Wood, 1935, p. 8)

Reflecting this awareness of the complexity of reading, there has been a relatively long history of attempts to classify reading disorders into different categories or 'subtypes' (see Boder, 1973; Mitterer, 1982; Fletcher \& Morris, 1986). Much of the earlier work in subtyping was not based on explicit theoretical models of the reading system, and therefore tended to be mainly descriptive. This is a useful way of characterizing a particular population, but it does not provide us with much insight into why children are reading in a particular way, or how they came to be that way. It also does not give us the power to make predictions about other types of reading profile that might be identifiable. More recently, however, researchers have used explicit theoretical models of the skilled reading system to make predictions about the particular patterns of developmental reading disorder that might be expected in the population (Olson et al., 1985; Castles \& Coltheart, 1993; Manis et al., 1996; Plaut et al., 1996; Coltheart et al., 2001). This has led to renewed interest in the subtypes themselves, and in the insights that they might also provide into the normal reading process.

In this review, I will outline the important contribution made by one particular theoretical model of reading - the dual route model - to the identification and understanding of different varieties of developmental dyslexia. I will begin by briefly outlining the model itself, and describing the particular types of reading disorder that would be predicted to occur based on this model. I will then review the evidence for the existence of these patterns of reading disability and outline advances that have been made in understanding their basis and aetiology. Finally, I will make some suggestions about how best to take research on heterogeneity in developmental dyslexia forward, moving away from distinct subtypes and more towards modelbased reading profiles.

\section{The dual route model of reading}

The dual route model represents skilled reading aloud as involving a system of processing modules which support two separate paths or routes (Coltheart, 1978; Morton \& Patterson, 1980; Coltheart et al., 1985, 1993, 2001). One route-the lexical route-involves reading by accessing a lexicon or memory store of previously seen written words. A second route-the non-lexical route-uses a set of translation rules to convert written graphemes into spoken phonemes. While both routes are activated by written inputs, the two routes differ in the types of input that they can read correctly. The lexical route will successfully process all words that a reader is familiar with, but will not recognize unfamiliar words or non-words (e.g., gop). The non-lexical route, on the other hand, will correctly sound out non-words, and regular words that follow typical grapheme-phoneme correspondences (e.g., market), but will make errors on irregular words that do not conform to typical correspondence rules (e.g., yacht). Therefore, on this model, lexical route functioning would typically be assessed by a test of irregular word reading, as these words can only be read 


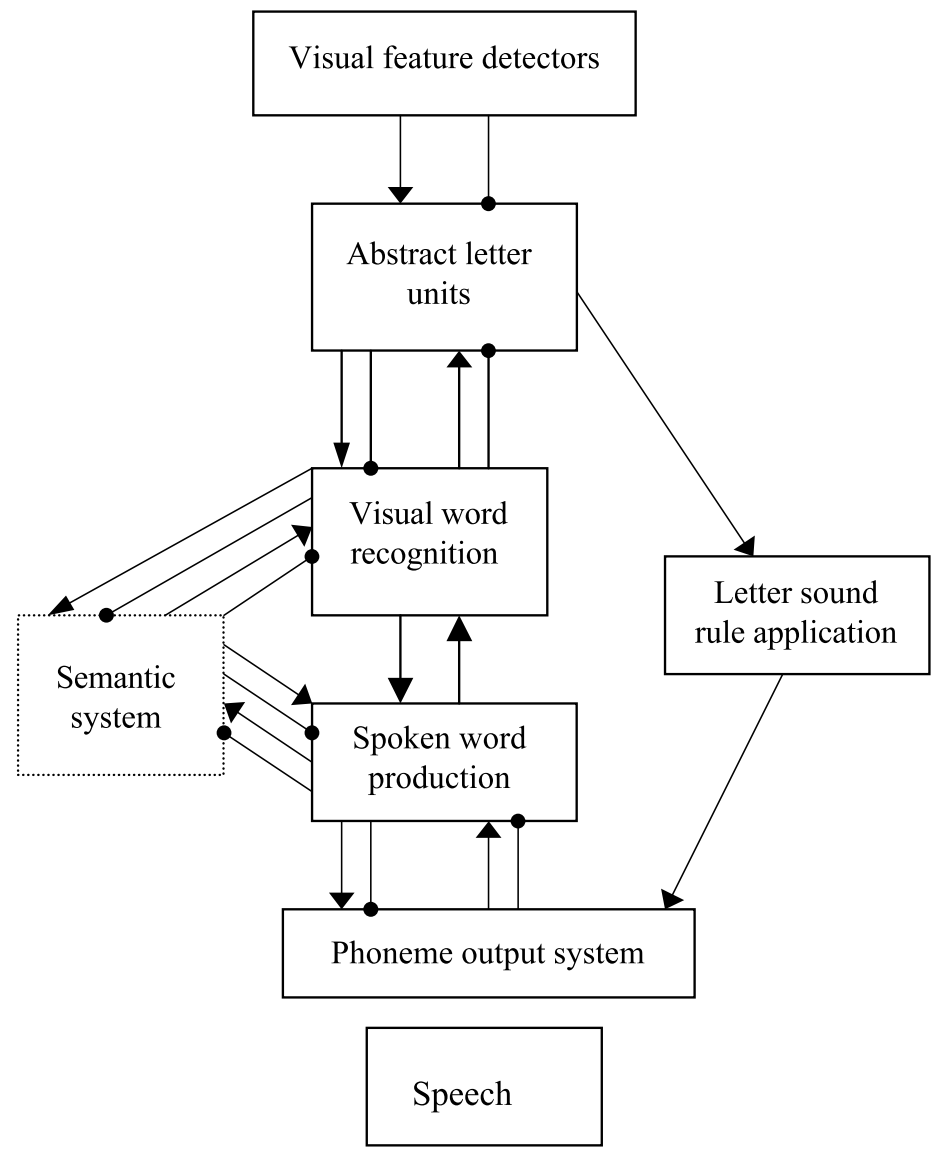

Figure 1. The dual route cascaded model of reading aloud, based on Coltheart et al. (2001)

correctly by the lexical route. Non-lexical route functioning would be assessed by a test of non-word reading, as these items can only be successfully pronounced via non-lexical rules. The architecture of the dual route model, based on Coltheart et al. (2001), is presented in Figure 1.

The prediction that different varieties or 'subtypes' of developmental dyslexia should be identifiable in the reading-impaired population falls naturally out of the architecture of the dual route model. As the lexical and non-lexical routes of the model are proposed to be at least partially independent, it follows that children learning to read may have varying degrees of difficulty acquiring one route or the other. They may have more difficulty acquiring the lexical route than the non-lexical route, resulting in better reading of non-words than irregular words, or, alternatively, they may have more difficulty acquiring the non-lexical route than the lexical route, resulting in better non-word reading than irregular word reading.

These specific patterns of reading deficit, were they to be identified, would be directly analogous to certain acquired dyslexic syndromes that have been observed in 
previously competent readers subsequent to brain injury. In acquired phonological dyslexia, patients have a specific difficulty in reading non-words, but their word reading is largely spared (Beauvois \& Derouesne, 1979; Funnell, 1983). In acquired surface dyslexia, non-word reading is normal, as is the reading of regular words that follow typical grapheme-phoneme rules, but performance on irregular words is very impaired (Marshall \& Newcombe, 1973; Bub et al., 1985; Weekes \& Coltheart, 1996). Proponents of the dual route model argue that to observe such parallels would not be surprising, since the same model of skilled reading is relevant to both acquired and developmental dyslexia (see Castles \& Coltheart, 1993). In acquired phonological dyslexia, the non-lexical route has been damaged; in developmental phonological dyslexia, it has not developed normally. In acquired surface dyslexia, the lexical route has been damaged; in developmental surface dyslexia, it has not developed normally. But the question remains: is there empirical evidence for these developmental dyslexia subtypes?

\section{Evidence for developmental forms of surface and phonological dyslexia}

Since the early 1980s there have been case-study reports of developmental forms of surface and phonological dyslexia. For example, Coltheart and colleagues (Coltheart et al., 1983) report the case of CD, a 17-year-old girl with an IQ exceeding 100 but a reading age of only 10 -years. Her reading performance closely resembled that of acquired surface dyslexics in that she was more successful in reading aloud regular words than irregular words. She also made frequent regularization errors, pronouncing irregular words as if they followed typical correspondence rules (e.g., reading pint as if it rhymed with 'mint'). In contrast to this, Temple and Marshall (1983; Temple, 1984) describe the case of HM, also a 17-year-old girl of average intelligence and with a reading age of around 10-years. Her reading showed a quite different pattern to that of CD: she could read aloud both regular and irregular words well, but performed very poorly on non-words and rare words, pointing to a developmental form of phonological dyslexia. Often, her responses to the non-words contained word components, suggesting that she used the lexical route in attempting to pronounce them. She made none of the regularization errors observed in CD's reading. Since then, several more cases of developmental surface and phonological dyslexia have been described (see Campbell \& Butterworth, 1985; Snowling \& Hulme, 1989; Goulandris \& Snowling, 1991; Hanley et al., 1992; Hanley \& Gard, 1995; Castles \& Coltheart, 1996; Samuelsson, 2000)

Castles and Coltheart sought to consolidate these findings in a larger group study. They examined irregular and non-word reading in 53 boys with dyslexia and 56 agematched controls. They found that approximately one third of the poor readers were in the normal range for their age on one task but below the 5 th percentile on the other. Specifically, eight children were identified as having pure developmental phonological dyslexia: their non-word reading was poor, compared with age-matched controls, but their irregular word reading was within normal range. Another 10 children were classified as having pure developmental surface dyslexia: their irregular 
word reading was poor but their non-word reading fell within normal range. A further 27 subjects were poor on both tasks, but nevertheless showed a significant discrepancy between their scores on the irregular word and non-word tasks. The remaining children were equally poor on both tasks. Castles and Coltheart concluded that, while deficits on the two reading tasks generally co-occur, irregular word reading and non-word reading can be dissociated, producing developmental forms of surface and phonological dyslexia at the extreme ends of the distribution.

Castles and Coltheart's basic finding has since been replicated in other samples of poor readers. Manis et al. (1996) examined patterns of reading difficulty in 51 children with dyslexia aged from 9- to 15-years, and identified two subgroups that were broadly comparable to Castles and Coltheart's surface and phonological groups. The two subgroups differed in predicted ways on irregular word reading and nonword reading, and also on other tasks that would be expected to be related to their reading deficits. Specifically, the phonological dyslexics were poor at analysing the sound structure of spoken non-words but were relatively good at making discriminations based on orthography. They were also less likely than surface dyslexics to produce regularization errors, but were more likely to produce visual approximations to target words. Stanovich et al. (1997) also report surface and phonological patterns in a slightly younger sample of poor readers (mean age $=9$-years), although a larger proportion of their sample was found to be poor on both irregular word and nonword reading.

In summary, although it must be remembered that most poor readers will be impaired in many aspects of reading, there is now compelling evidence for heterogeneity within the developmental dyslexic population. Within a sample of poor readers referred by parents or teachers as having a reading problem, and who perform poorly on standardized tests of reading, there will be some children whose difficulty specifically involves storing or accessing word-specific information and another group whose difficulty is with the translation of letters into sounds. Although the question of exactly how to characterize these subgroups remains controversial (see Manis et al., 1996 and Harm \& Seidenberg, 1999, for alternative theoretical accounts of the subtypes), their identification is unquestionably attributable in large part to the predictive power of the dual route model.

\section{What underlies different types of reading disability?}

Unlike in acquired dyslexia, where the cause of the reading impairment can be clearly attributed to a brain insult, the cause of developmental surface and phonological dyslexia requires further exploration. It is generally assumed that, since reading is a learned skill, some aspect of that learning process must have been disrupted in developmental dyslexia. And, since developmental surface and phonological dyslexia are characterized by quite different kinds of reading difficulty, it is also likely that the causal factors will differ to some degree across these subtypes. The dual route model, as a model of the skilled reading process rather than of learning to read, cannot tell us what these different causal factors might be. However, it does allow us 
to focus our explorations of causality on precisely defined reading sub-processes and this, I would argue, has led to a more sophisticated examination of reading acquisition processes than in those cases where reading has been treated as an omnibus skill. In the next sections, I will review what is known to date about the factors that might underlie different types of reading impairment.

\section{Causes of developmental phonological dyslexia}

There is a single dominant account of the basis of developmental phonological dyslexia, and that is that it is associated with a pervasive general language deficit. Specifically, children with this disorder are proposed to have impairments in phonological awareness. Broadly defined, phonological awareness refers to the ability to perceive and manipulate the sounds of spoken words (Goswami \& Bryant, 1990). It encompasses awareness of the most basic speech units of a language - phonemesas well as larger units such as rimes and syllables, and is typically measured by tasks which require the participant to mentally delete, segment or blend such sounds in presented spoken words.

There have been numerous reports of phonological awareness deficits in cases of developmental phonological dyslexia, suggesting that indeed there is an association between this language skill and non-lexical reading ability (see Campbell \& Butterworth, 1985; Snowling et al., 1986; Hulme \& Snowling, 1992; Hanley \& Gard, 1995; Manis et al., 1996; Castles et al., 1999; Valdois et al., 2003). Although the mechanism by which deficits in phonological awareness might have affected reading acquisition in these cases is debated, it is widely argued that, since letters usually represent individual phonemes in alphabetic languages, a child needs to be aware of the phonemic segments in spoken words in order to be able to learn effectively about their correspondences with letters (Liberman, 1973; Liberman et al., 1974). Thus, phonological awareness, at least in rudimentary form, is a prerequisite for the normal development of non-lexical reading skills.

However, although phonological awareness is clearly an important factor to consider, it may not be the whole story in accounting for phonological dyslexia. As Castles and Coltheart (2004) discuss at length, it is extremely difficult to determine whether phonological awareness deficits actually cause non-lexical reading impairments, or whether they are the result of those impairments. There is growing evidence that children use written word or orthographic knowledge to assist their performance when carrying out phonological awareness tasks. For example, they may visualize the spelling of the spoken words or non-words presented to them and perform their manipulations on the letters rather than the sounds (Ehri \& Wilce, 1980; Stuart, 1990; Castles et al., 2001). Therefore, it may be that children with dyslexia perform more poorly on phonological awareness tasks, not because their oral language skills per se are impaired, but because this additional orthographic strategy is not available to them.

In addition, it does not appear to be the case that non-word reading deficits and phonological awareness deficits must always co-occur. Hart (2004) has recently 
described a severe case of developmental phonological dyslexia in which performance on a range of tests of phonological awareness was normal. SE was a 13year-old girl with an average IQ, who was performing approximately two standard deviations below the mean for her age in non-word reading but normally at irregular word reading. Her case report suggested no history of expressive language, receptive language or phonological deficits. On testing, she was found to perform at or above average for her age on auditory phoneme discrimination, non-word repetition, syllable deletion, syllable manipulation, phoneme deletion and phoneme manipulation.

If phonological dyslexia does not necessarily have its basis in a general language deficit, how is the frequent co-morbidity of this particular kind of reading disorder and phonological awareness deficits to be accounted for? On a dual route account, the basic deficit in phonological dyslexia lies within the reading system itself, at the level of the grapheme-phoneme conversion system, not within a more general language processing system. To use the terminology introduced by Jackson and Coltheart (2001), this is the proximal cause of their reading performance. However, a deficit in this reading subsystem will, in itself, have a cause, which may be an impairment in some aspect of perceptual, cognitive or language processing that is required for the development of that subsystem. This is referred to as a distal cause (Jackson \& Coltheart, 2001). One such distal cause might be an impairment in phonological awareness. And indeed, such an impairment would be a likely candidate for disrupting the development of the non-lexical route, as learning grapheme-phoneme correspondences must presumably require at least some capacity for discriminating and segmenting phonemes. However, importantly, on this account: (a) phonological awareness deficits need not necessarily be the cause of non-lexical reading deficits; and (b) may represent just one of a number of possible causes of such deficits. In other words, on a dual route account of developmental phonological dyslexia, an impairment in phonological awareness represents a possible distal, but not a proximal, cause of phonological dyslexia.

\section{Causes of developmental surface dyslexia}

The concept of proximal and distal causes of developmental dyslexia is also useful when considering the aetiology of developmental surface dyslexia. Indeed, here, the potential distal causes of the difficulty in acquiring lexical skills appear to be many. While developmental phonological dyslexia is widely attributed to phonological language deficits, there are numerous hypotheses concerning the nature of the underlying deficit in surface dyslexia, ranging from cognitive and perceptual impairments through to environmental factors. As we will see, the evidence for any one factor causing all forms of lexical reading impairment is weak.

Contributing significantly to the debate on causes of developmental surface dyslexia have been the findings of Manis et al. (1996) and others regarding the performance of these kinds of poor readers compared to reading age matched controls. Reading-age matched controls are evident in younger normal readers, who are reading at the same overall level as their matched dyslexic groups. Based on comparisons 
with this group, Manis et al. found that their subgroup of phonological dyslexic children was poorer at non-word reading on average than both chronological and reading age matched controls, showing what has been referred to as a deviant pattern of development (Coltheart, 1987). Their subgroup of surface dyslexic children, on the other hand, was no poorer on average at irregular word reading than the reading-age matched controls. They therefore concluded that the surface dyslexic pattern is best described as a general developmental delay rather than as a deviant reading pattern. Indeed, based on these findings, some theorists have questioned the validity of treating surface dyslexia as a genuine 'subtype', associated specifically with lexical reading impairments (Harm \& Seidenberg, 1999).

What factor or factors, then, might lead children to be generally slow or delayed in acquiring the word-specific reading skills required to read irregular words fluently? A definitive answer to this question has proven elusive. In fact, it has been difficult to consistently and reliably distinguish children with surface dyslexia from other readers on any measures other than the word-specific reading tasks used to identify them in the first place. There are several abilities in which they clearly do not show delays: Children with pure surface dyslexia are not impaired on non-lexical reading skills, as they are typically identified on the basis of their normal performance here. Consistent with this, phonological awareness skills are also generally unimpaired (Hanley \& Gard, 1995; Manis et al., 1996). There is also no apparent evidence for semantic or vocabulary impairments in these children (Castles \& Coltheart, 1993, 1996).

One area where delays might have been expected to be evident in surface dyslexia is in the domain of print exposure. Ann Cunningham and Keith Stanovich have for several years been exploring the relationship between children's word recognition skills and their exposure to, and experience of, written materials in their home and school environments (Cunningham \& Stanovich, 1990, 1991, 1993, 1997). Measures of this construct are typically in the form of checklists, which ask children to mark the titles of books, magazines or other written materials that they are familiar with. However, although print exposure is modestly correlated with lexical reading skills in unselected groups of developing readers, there is little evidence that surface dyslexia is widely attributable to weaknesses in this domain. Castles et al. (1999) found that a group of surface dyslexics performed more poorly than other kinds of dyslexics on some print exposure measures in their large twin sample. However, the effect size was very small and seemed unlikely to be sufficient to account for the large differences between the groups in lexical reading skills. Gustafson (2001) reports lower scores for surface dyslexics relative to reading age matched controls on the question 'How many books are there in your home?', but there were no group differences at all on questions related to how often the children read books for fun, how often they read cartoons, or how often they read weekly magazines or newspapers. Other studies have similarly produced no significant differences between groups on print exposure measures (Manis et al., 1996).

The other major proposed locus of lexical reading delays has been on visual memory and visual processing deficits of various forms. Goulandris and Snowling (1991) report evidence for impaired visual recognition and visual retention skills in 
their surface dyslexic subject, JAS. Samuelsson (2000), reports the case of EBON, who shows reduced priming compared to controls for visually presented words but not for auditorily presented words, suggesting an implicit visual memory disorder, and Valdois and colleagues (2003) represent the deficits of their case of surface dyslexia, Nicolas, in terms of a visual attentional disorder. However, although these deficits appear to successfully characterize these individual cases, they do not seem to be consistently found in surface dyslexia. Castles and Coltheart (1996) report no evidence for visual memory deficits in their case, $\mathrm{LH}$, and group studies indicate that, for the most part, surface dyslexics do not appear to display basic visualperceptual deficits (Spinelli et al., 1997; Cestnick \& Coltheart, 1999; Williams et al., 2003).

What then, are we to conclude about causes of developmental surface dyslexia? The answer, once again, would seem to lie in the acknowledgement of likely heterogeneity in the distal causes of these reading deficits. Just as phonological dyslexia may be, but is not necessarily, caused by phonological language impairments, surface dyslexia may be, but is not necessarily caused by a lack of print exposure or impairments in visual processing. This variability is perhaps even more likely given the evidence for a delay, rather than a deviance, pattern in surface dyslexia. If lexical development is delayed, it seems reasonable to hypothesize that such a delay might be attributable to a range of different factors. Different children may have developed surface dyslexia for different reasons, and any individual child's surface dyslexia may have been caused by a number of different factors.

A further reason for the heterogeneity in the distal causes of surface dyslexia lies in the fact that all children diagnosed with surface dyslexia are unlikely to have exactly the same kind of lexical reading deficit. Even within this syndrome, there is likely to be variability in the proximal cause. Consultation of Figure 1 indicates that there are three processing units that are unique to the lexical pathway of the reading system: visual word recognition of familiar written words, the semantic system, where known words' meanings are stored, and spoken word production of familiar words. An impairment in any one of these processing systems would potentially produce a specific deficit in learning to read aloud irregular words, or developmental surface dyslexia. For this reason, there would seem to be a strong case for dispensing with summary labels such as surface and phonological dyslexia, and moving towards providing individual characterizations of reading disorders based on model-driven testing. I will now turn to discussing this idea in more detail.

\section{Beyond subtypes: moving towards model-based diagnoses of dyslexia}

The initial aims of the dual-route based subtyping work reported here were twofold: (a) to show that developmental dyslexia is not a homogeneous disorder; and (b) to make predictions about the nature of that heterogeneity using a model of skilled reading. It would seem that these aims have now largely been achieved. The dissociations between irregular word and non-word reading predicted by the dual route model have been documented in several group studies (Castles \& Coltheart, 1993; 
Manis et al., 1996; Stanovich et al., 1997), and the subgroups formed have been validated using other measures. So the question arises: where do we go from here in subtyping research?

At this point, it may be helpful to revisit some comments made by Coltheart (1984) in relation to acquired dyslexic syndromes:

The concept of the syndrome has been a useful one in developing work relating acquired dyslexic syndromes to reading models. However, its usefulness is likely to be short lived. The reason is that, if a dyslexic syndrome is a specific pattern of preservations and impairments of reading abilities ... and if a modular model of reading is appropriate, if follows that there are many different possible dyslexic syndromes. Any unique pattern of impairments to ... the model will produce a unique syndrome. (Coltheart, 1984, p. 370)

These points would seem to apply equally to research on developmental dyslexia subtypes. As noted above, developmental surface dyslexia, although more informative as a label than simply 'dyslexia', is not a unitary syndrome. There are several different processing modules involved in reading via the lexical route, and, as such, there are a number of different forms of reading impairment that might present as a deficit in reading irregular words. Of course, we could decide to identify a new syndrome label for each of these 'subtypes' of surface dyslexia: word recognition surface dyslexia, semantic surface dyslexia, spoken word production surface dyslexia and so on. However, taken to it's logical extreme, such an exercise seems somewhat futile. Consider, for example, if the model of language processing on which we were basing our assessments was that of Howard and Franklin (1989). This particular model contains 27 separate components. Therefore, the number of possible separate syndromes we could identify would be $2^{27}-1$, or $2,220,075$ !

I would like to propose, therefore, that the object of study in exploring developmental dyslexia and its causes should not be subtypes per se but the individual developmental dyslexic child. Each child with a reported reading problem should be assessed in the context of an explicit theoretical model of reading, and their pattern of strengths and deficits characterized in terms of that model. Investigations of the aetiology of reading disorders would then be pursued by exploring the distal causes of deficits displayed by individual children in specific processing components of the model. At no point would a particular subtype need to be designated.

If we are to focus our investigations on the individual dyslexic child, how, then, do we generalize our findings? Again, we can turn to Coltheart's (1984) comments on acquired dyslexia (substituting 'child' for 'patient'):

The assumption that a single model should be applicable to all patients allows each new patient to be an appropriate source of data for testing the model; and this permits one to generalize from previous to future patients even if one has rejected the policy of thinking in terms of syndromes (Coltheart, 1984, p. 371)

With this approach, I expect that researchers in education and psychology will continue to make great advances in uncovering the nature and causes of the developmental dyslexias. 


\section{Acknowledgments}

Estelle Doctor is thanked for her comments on an earlier version of this manuscript.

\section{Notes on contributor}

Anne Castles is an Associate Professor in the Department of Psychology, University of Melbourne. She completed her Ph.D. on subtypes of dyslexia in 1993, and maintains a strong research interest in variability within the reading impaired population. Her research also explores potential causes of dyslexia, including genetic, perceptual and language factors. She serves on the Editorial Board of Scientific Studies of Reading and European fournal of Cognitive Psychology.

\section{References}

Beauvois, M. F. \& Derouesne, J. (1979) Phonological alexia: three dissociations, fournal of Neurology, Neurosurgery \& Psychiatry, 42, 1115-1124.

Boder, E. (1973) Developmental dyslexia: a diagnostic approach based on three typical readingspelling patterns, Developmental Medicine E Child Neurology, 15, 663-687.

Bub, D., Cancelliere, A. \& Kerstesz, A. (1985) Whole word and analytic translation of spelling to sound in a non-semantic reader, in: K. E. Patterson, J. C. Marshall \& M. Coltheart (Eds) Surface dyslexia: neuropsychological and cognitive studies of phonological reading (London, Lawrence Erlbaum).

Campbell, R. \& Butterworth, B. (1985) Phonological dyslexia and dysgraphia in a highly literate subject: a developmental case with associated deficits of phonemic processing and awareness, Quarterly fournal of Experimental Psychology, 35A, 435-475.

Castles, A. \& Coltheart, M. (1993) Varieties of developmental dyslexia, Cognition, 47, 149-180.

Castles, A. \& Coltheart, M. (1996) Cognitive correlates of developmental surface dyslexia: a single case study, Cognitive Neuropsychology, 13, 25-50.

Castles, A. \& Coltheart, M. (2004) Is there a causal link from phonological awareness to success in learning to read?, Cognition, 91, 77-111.

Castles, A., Datta, H., Gayan, J. \& Olson, R. K. (1999) Varieties of developmental reading disorder: Genetic and environmental influences, fournal of Experimental Child Psychology, 72, 73-94.

Castles, A., Holmes, V. M., Neath, J. \& Kinoshita, S. (2003) How does orthographic knowledge influence performance on phonological awareness tasks?, Quarterly fournal of Experimental Psychology, 56A, 445-467.

Cestnick, L. \& Coltheart, M. (1999) The relationship between language-processing and visualprocessing deficits in developmental dyslexia, Cognition, 71, 231-255.

Coltheart, M. (1978) Lexical access in simple reading tasks, in: G. Underwood (Ed.) Strategies of information processing (London, Academic Press).

Coltheart, M. (1984) Acquired dyslexias and normal reading, in: R. N. Malatesha \& H. A. Whitaker (Eds) Dyslexia: a global issue (The Hague, Martinus Hijhoff).

Coltheart, M. (1987) Varieties of developmental dyslexia: a comment on Bryant and Impey, Cognition, 27, 97-101.

Coltheart, M., Curtis, B., Atkins, P. \& Haller, M. (1993) Models of reading aloud: dual route and parallel-distributed-processing approaches, Psychological Review, 100, 589-608.

Coltheart, M., Masterson, J., Byng, S., Prior, M. \& Riddoch, J. (1983) Surface dyslexia, Quarterly fournal of Experimental Psychology, 37A, 469-495. 
Coltheart, M., Rastle, K., Perry, C., Langdon, R. \& Ziegler, J. (2001) DRC: a dual route cascaded model of visual word recognition and reading aloud, Psychological Review, 108, 204-256.

Cunningham, A. E. \& Stanovich, K. E. (1990) Assessing print exposure and orthographic processing skill in children: a quick measure of reading experience, fournal of Educational Psychology, $82,733-740$.

Cunningham, A. E. \& Stanovich, K. E. (1991) Tracking the unique effects of print exposure in children: associations with vocabulary, general knowledge, and spelling, fournal of Educational Psychology, 83, 264-274.

Cunningham, A. E. \& Stanovich, K. E. (1993) Children's literacy environments and early word recognition skills, Reading E Writing: An Interdisciplinary fournal, 5, 193-204.

Cunningham, A. E. \& Stanovich, K. E. (1997) Early reading acquisition and its relation to reading experience and ability ten years later, Developmental Psychology, 33, 934-945.

Ehri, L. C. \& Wilce, L. S. (1980) The influence of orthography on readers' conceptualisation of the phonemic structure of words, Applied Psycholinguistics, 1, 371-385.

Fletcher, J. M. \& Morris, R. (1986) Classification of disabled learners: beyond exclusionary definitions, in: S. J. Ceci (Eds) Handbook of social and neuropsychological aspects of learning disabilities, Vol 2 (Hilssdale, NJ, Erlbaum).

Funnell, E. (1983) Phonological processes in reading: new evidence from acquired dyslexia, British fournal of Psychology, 74, 159-180.

Goswami, U. \& Bryant, P. (1990) Phonological skills and learning to read (London, Lawrence Erlbaum Associates).

Goulandris, N. K. \& Snowling, M. (1991) Visual memory deficits: a plausible cause of developmental dyslexia? Evidence from a single case study, Cognitive Neuropsychology, 8, 127-154.

Gustafson, S (2001) Cognitive abilities and print exposure in surface and phonological types or reading disability, Scientific Studies of Reading, 5, 351-375.

Hanley, R., Hastie, K. \& Kay, J. (1992) Developmental surface dyslexia and dysgraphia: an orthographic processing impairment, The Quarterly fournal of Experimental Psychology, 44, 285-319.

Hanley, J. R. \& Gard, F. (1995) A dissociation between developmental surface and phonological dyslexia in two undergraduate students, Neuropsychologia, 33, 909-914.

Harm, M. W. \& Seidenberg, M. S. (1999) Phonology, reading acquisition, and dyslexia, insights from connectionist models, Psychological Review, 106, 491-528.

Hart, L. (2004) Developmental surface and phonological dyslexia. Unpublished Ph.D. thesis, Macquarie University, Sydney, Australia.

Howard, D. \& Franklin, S. (1989) Missing the meaning?: a cognitive neuropsychological study of processing of words by an aphasic patient (Boston, MIT Press).

Hulme, C. \& Snowling, M. J. (1992) Deficits in output phonology: an explanation of reading failure?, Cognitive Neuropsychology, 9, 47-72.

Jackson, N. E. \& Coltheart, M. (2001) Routes to reading success and failure: CC an integrated cognitive psychology of atypical reading (Hove, Lawrence Erlbaum Associates).

Liberman, I. Y. (1973) Segmentation of the spoken word and reading acquisition, Bulletin of the Orton Society, 23, 65-77.

Liberman, I. Y., Shankweiler, D., Fischer, F. W. \& Carter, B. (1974) Explicit syllable and phoneme segmentation in the young child, fournal of Experimental Child Psychology, 18, 201-212.

Manis, F. R., Seidenberg, M. S., Doi, L. M., McBride-Chang, C. \& Peterson, A. (1996) On the bases of two subtypes of developmental dyslexia, Cognition, 58, 157-195.

Marshall, J. C. \& Newcombe, F. (1973) Patterns of paralexia: a psycholinguistic approach, fournal of Psycholinguistic Research, 2, 175-199.

McIntyre, G. A. \& Wood, W (1935) The standardization of an Australian reading test (Melbourne, Melbourne University Press).

Mitterer, J. O. (1982) There are at least two kinds of poor readers: whole word poor readers and recoding poor readers, Canadian fournal of Psychology, 36, 445-461. 
Morton, J. \& Patterson, K. E. (1980) A new attempt at an interpretation or an attempt at a new interpretation, in: M. Coltheart, K. E. Patterson \& J. C. Marshall (Ed.) Deep dyslexia (London, Routledge \& Kegan Paul).

Olson, R. K., Kliegl, R., Davidson, B. J. \& Foltz, G. (1985) Individual and developmental differences in reading disability, in: G. E. MacKinnon \& T. G. Waller (Eds) Reading research: advances in theory and practice (New York, Academic Press), 1-64.

Plaut, D. C., McClelland, J. L., Seidenberg, M. S. \& Patterson, K. (1996) Understanding normal and impaired word reading: computational principles in quasi-regular domains, Psychological Review, 103, 56-115.

Samuelsson, S. (2000) Converging evidence for the role of occipital regions in orthographic processing: a case of developmental surface dyslexia, Neuropsychologia, 38, 351-362.

Snowling, M. J. \& Hulme, J. (1989) A longitudinal case study of developmental phonological dyslexia, Cognitive Neuropsychology, 6, 379-401.

Snowling, M., Stackhouse, J. \& Rack, J. (1986) Phonological dyslexia and dysgraphia: a developmental analysis, Cognitive Neuropsychology, 3, 309-339.

Spinelli, D., Angelelli, P., De Luca, M., Di Pace, E., Judica, A. \& Zoccolotti, P. (1997) Developmental surface dyslexia is not associated with deficits in the transient visual system, NeuroReport, 8, 1807-1812.

Stanovich, K. E., Siegel, L. S. \& Gottardo, A. (1997) Converging evidence for phonological and surface subtypes of reading disability, Fournal of Educational Psychology, 89, 114-127.

Stanovich, K. E. \& West, R. F. (1989) Exposure to print and orthographic processing, Reading Research Quarterly, 24, 402-433.

Stuart, M. (1990) Processing strategies in a phoneme deletion task, Quarterly fournal of Experimental Psychology, 42A, 305-327.

Temple, C. M. \& Marshall, J. C. (1983) A case study of developmental phonological dyslexia, British fournal of Psychology, 74, 517-533.

Valdois, S., Bosse, M. L., Ans, B., Carbonnel, S., Zorman, M., David, D. \& Pellat, J. (2003) Phonological and visual processing deficits can dissociate in developmental dyslexia: evidence from two case studies, Reading E Writing, 16, 541-572.

Weekes, B. \& Coltheart, M. (1996) Surface dyslexia and surface dysgraphia: treatment studies and their theoretical implications, Cognitive Neuropsychology, 13, 277-315.

Williams, M. J., Stuart, G. W., Castles, A. \& McAnally, K. (2003) Contrast sensitivity in subgroups of developmental dyslexia, Vision Research, 43, 467-477. 